\section{Análise bioeconômica de períodos de suplementação proteico-energética na estação seca para novilhas Nelore em pastagem diferida de Urochloa decumbens}

\author{
[Bioeconomic analysis of protein-energy supplementation periods in dry season for \\ Nellore heifers in stockpiled pastures of Urochloa decumbens] \\ P.H.F. Silva ${ }^{1}$, C.A.B. Carvalho ${ }^{2}$, P. Malafaia ${ }^{2}$, F.Z. Garcia ${ }^{2}$, \\ A.A.C. Peres ${ }^{3}$, P.M. Souza ${ }^{4}$, R.P. Barbero ${ }^{2}$, R.L. Ferreira ${ }^{2}$ \\ ${ }^{1}$ Universidade Federal Rural de Pernambuco - Recife, PE \\ ${ }^{2}$ Universidade Federal Rural do Rio de Janeiro - Seropédica, RJ \\ ${ }^{3}$ Universidade Federal Fluminense - Niterói, RJ \\ ${ }^{4}$ Universidade Estadual do Norte Fluminense - Campos dos Goytacazes, RJ
}

P.H.F. Silva

https://orcid.org/0000-0002-0794-4499 C.A.B. Carvalho https://orcid.org/0000-0002-1096-5370

P. Malafaia
hittps://orcid.org/0000-0002-7732-5159 F.Z. Garcia hitps://orcid.org/0000-0003-0667-712X https://orcid.org/0000-0001-9037-0715 P.M. Souza https://orcid.org/0000-0002-5788-915X R.P. Barbero https://orcid.org/0000-0002-1577-395X https://orcid.org/0000-0002-1167-2035

\title{
RESUMO
}

A suplementação proteico-energética (SPE) é uma estratégia adequada à bovinocultura de corte no período seco do ano, embora sua adoção equivocada possa comprometer seu benefício/custo. O objetivo deste estudo foi avaliar o desempenho de novilhas Nelore em pastagem diferida de Urochloa decumbens sob dois períodos de SPE, e realizar análise econômica desses sistemas de produção. O experimento foi conduzido sob delineamento inteiramente ao acaso, com 147 e 55 dias de SPE (sistemas 1 e 2, respectivamente), de 21/06 a 15/11/2016, com 16 e 20 novilhas nos sistemas 1 e 2, respectivamente. Os dados de desempenho foram analisados utilizando-se o PROC MIXED do SAS ${ }^{\circledR}$, e as médias comparadas por PDIFF $(\mathrm{P}<0,05)$. Os pesos médios foram semelhantes $(\mathrm{P}>0,05)$ entre os sistemas de produção nas pesagens de 21/06, 12/07, 02/08, 23/08 e 15/11/2016. Os valores presentes líquidos foram positivos sob a taxa anual de desconto de $4 \%$, sendo viáveis financeiramente. Por apresentarem taxa interna de retorno superior à taxa mínima de atratividade, os sistemas foram atrativos para investimento. Foi obtido balanço econômico positivo de $\mathrm{R} \$ 25,26 /$ animal para substituição do sistema 1 pelo sistema 2 . A redução de 92 dias na SPE proporciona desempenho semelhante entre novilhas e maior eficiência econômica do sistema de produção.

Palavras-chave: balanço econômico, crescimento compensatório, indicadores econômicos de rentabilidade, suplemento proteico-energético

\begin{abstract}
Protein-energy supplementation (SPE) is an adequate strategy for beef cattle during drought season of the year, although the wrong adoption might compromise its cost/benefit ratio. The aim of this study was to evaluate Nellore heifers' performance under SPE periods and to draw economic analysis of production systems. The experiment was conducted under a completely randomized design, with two systems: 147 and 55 days of SPE (Systems 1 and 2), from 06/21/2016 to 11/15/2016, with 16 and 20 heifers to Systems 1 and 2, respectively. Performance data were analyzed by SAS® PROC MIXED and means compared by PDIFF $(P<0.05)$. The weight means were similar between the production systems $(P>0.05)$ at weighing of 06/21,07/12, 08/02, 08/23 and 11/15/2016. The net present values were positive under annual discount rate of 4\%, being financially viable. By presenting internal return rate higher than the minimum attractiveness rate, the systems were attractive for investment. Positive economic balance was obtained of $R \$ 25.26 /$ animal to replace System 1 by 2. The reduction of 92 days in SPE provides similar performance between Nellore heifers and greater economic efficiency of the production system.
\end{abstract}

Keywords: compensatory gain, economic balance, economic indicators of profitability, protein-energy supplement

Recebido em 24 de janeiro de 2018

Aceito em 9 de novembro de 2018

E-mail: pehenrique1709@gmail.com 


\section{INTRODUÇÃO}

A estacionalidade da produção forrageira é um entrave para os sistemas de produção a pasto. No período seco do ano, o acréscimo nas concentrações de carboidratos fibrosos de lenta degradação ruminal e a redução do teor de nitrogênio nas forragens podem comprometer o desempenho animal (Reis et al., 2013). Portanto, quando se objetiva aumentar o desempenho de animais em ambientes pastoris, é necessário utilizar estratégias de suplementação (Zervoudakis et al., 2010). Em função disso, o uso de suplemento proteico-energético (SPE) promove fornecimento adicional de nitrogênio e energia para ruminantes que consomem forragens de baixa qualidade (Malafaia et al., 2007). Entretanto, para que a SPE seja eficaz, a oferta de forragem é de fundamental importância e, para tal, os pastos diferidos devem apresentar, no mínimo, 2500 a $3000 \mathrm{~kg} \mathrm{ha}^{-1}$ de massa de forragem e devem ser manejados sob taxa de lotação adequada, para garantir seletividade e desempenho satisfatórios (Silva et al., 2009).

No Brasil, a fase de recria de novilhas dura em média 30 meses, fato que reduz a eficiência reprodutiva do rebanho (Andrade, 1990). Logo, estratégias de suplementação de custo reduzido, como o diferimento de pastagens e a SPE, podem reduzir a duração da recria de novilhas (Medeiros et al., 2010). Usualmente, recomendase que o fornecimento de SPE ocorra durante todo o período seco do ano, embora tal medida não seja necessariamente exigida para manter o desempenho animal, como também não é ideal do ponto de vista econômico. Por outro lado, sabe-se que, quando há realimentação dos bovinos, posterior a uma eventual restrição nutricional, comumente se verifica "crescimento compensatório" deles, fenômeno no qual o ganho de peso dos animais submetidos à restrição nutricional é acentuado quando comparado àquele de animais que não sofreram essa restrição. Vale destacar que esse efeito também pode ser explicado pelo aumento da ingestão de matéria seca e consequente elevação proporcional do peso da digesta no trato gastrintestinal (Sainz, 1995; Mota, 2015).

Esse cenário pode justificar a adoção de períodos parciais de SPE e ser de grande relevância para o aumento da eficiência econômica de sistemas de produção a pasto (Malafaia et al., 2007).
A metodologia de orçamento parcial comparativo representa uma forma simplificada de análise econômica que auxilia a tomada de decisão nas atividades agropecuárias (Mota et al., 2015), pois seu princípio básico é o cálculo direto dos custos e benefícios de cada tratamento ou sistema de produção estudado. Isso porque os cálculos de margem bruta são determinados sem consideração de custos fixos (Noronha, 1981).

Por outro lado, alguns indicadores econômicos são importantes para determinação da eficiência econômica dos sistemas de produção, como o valor presente líquido (VPL) e a taxa interna de retorno (TIR). O VPL é o somatório dos valores de fluxo de caixa adequados às diferentes taxas de descontos ao longo do tempo e indica viabilidade de implantação de um determinado sistema de produção ou projeto de investimento. Dessa forma, quando o VPL é inferior a zero, o sistema de produção é considerado inviável. Já a TIR, conceituada como a taxa de juros (desconto) que iguala o VPL do sistema de produção a zero, demonstra atratividade da implantação do sistema de produção. Assim, determinada atividade pecuária é atrativa se a TIR for superior ao custo de oportunidade de capital (Contador, 1988; Peres et al., 2015). Assim, é possível traçar uma análise bioeconômica consistente sobre a comparação de sistemas de produção, bem como as vantagens financeiras (lucro) na substituição de uma determinada tecnologia por outra, por exemplo, diferentes períodos de SPE.

Com base nesse contexto, o objetivo deste estudo foi avaliar a viabilidade econômica do desempenho de novilhas Nelore recriadas em pastos diferidos de Urochloa decumbens, submetidas a dois períodos de suplementação proteico-energética durante a estação seca do ano, com base no uso de indicadores de eficiência econômica e orçamento parcial comparativo.

\section{MATERIAL E MÉTODOS}

O estudo foi realizado na Fazenda Santana, em Valença - RJ (4342' $11^{\prime \prime} \mathrm{O}$ e $22^{\circ} 14^{\prime} 46^{\prime \prime} \mathrm{S}$ ), cuja altitude média é 551 metros e o clima é Cfa (subtropical úmido, segundo Köppen). A área experimental foi compreendida de dois pastos de Urochloa decumbens, com aproximadamente 8,0 hectares cada, previamente diferidos por 121 dias 
(22/02 a 21/06/2016) após adubação com 60kg $\mathrm{ha}^{-1}$ de N, 50kg ha ${ }^{-1}$ de $\mathrm{P}_{2} \mathrm{O}_{5}$ e $50 \mathrm{~kg} \mathrm{ha}^{-1}$ de $\mathrm{K}_{2} \mathrm{O}$.

O experimento teve início em 21/06/2016 e término em 15/11/2016, respaldado pelo Ceua-IZ da UFRRJ, sob número de protocolo 23083.00822/2015-56. Este, foi estabelecido sob delineamento inteiramente ao acaso, com dois períodos de SPE (147 e 55 dias) durante a estação seca do ano (sistemas 1 e 2, respectivamente). A SPE teve início em 21/06/2016 e 21/09/2016, para as novilhas suplementadas por 147 (sistema 1) e 55 dias (sistema 2), respectivamente. O término da SPE ocorreu em 15/11/2016 para ambos os sistemas. Foram utilizadas 36 novilhas mestiças Nelore, distribuídas em dois lotes homogêneos quanto ao grupo racial (3/4 Nelore), categoria (novilhas), idade $(15 \pm 1$ meses) e peso corporal $(296 \pm 4 \mathrm{~kg})$. Com o objetivo de proporcionar similares ofertas de forragem iniciais para ambos os sistemas, o sistema 1 foi composto por 16 , e o sistema 2 por 20 novilhas. Cada animal foi considerado uma repetição e ambos os sistemas foram manejados sob lotação contínua. As novilhas do sistema 2 foram suplementadas apenas com sal branco $(\mathrm{NaCl})$ de 21/06/2016 até o início da SPE, em 21/09/2016.

As avaliações de oferta de forragem (OF) foram realizadas em intervalos de 21 dias. No período de 21/06/2016 a 04/10/2016, houveram reduções de 43,2 para $6,0 \mathrm{~kg}$ MS $100 \mathrm{~kg}^{-1}$ no sistema 1 e de 43,6 para $6,7 \mathrm{~kg}^{\mathrm{MS}} 100 \mathrm{~kg}^{-1}$ no sistema 2 . As OF não foram limitantes para o desempenho animal durante este período, segundo Silva et al. (2009). $\mathrm{Na}$ última avaliação (25/10/2016), as OF foram 4,5 e $4,9 \mathrm{~kg} \mathrm{MS} 100 \mathrm{~kg}^{-1}$ para os sistemas 1 e 2 , respectivamente.

A SPE foi ofertada à vontade aos animais em cochos de $30 \times 40 \times 15 \mathrm{~cm}$ por UA, e o sal branco em outros cochos com $15 \times 20 \times 6 \mathrm{~cm}$ por UA. Além disso, a expectativa de consumo do suplemento proteico-energético foi de $0,1 \%$ do peso corporal, respectivamente, conforme indicação de Marino e Medeiros (2015). A fórmula do suplemento proteico-energético (SPE) foi composta de: $150 \mathrm{~g} \mathrm{~kg}^{-1}$ de farelo de soja; $600 \mathrm{~g} \mathrm{~kg}^{-1}$ de fubá de milho; $100 \mathrm{~g} \mathrm{~kg}^{-1}$ de ureia; e $150 \mathrm{~g} \mathrm{~kg}^{-1}$ de sal branco. A estimativa de sua composição química foi de: $916 \mathrm{~g} \mathrm{~kg}^{-1} \mathrm{de} \mathrm{MS}$; $399 \mathrm{~g} \mathrm{~kg}^{-1}$ de PB; $105 \mathrm{~g} \mathrm{~kg}^{-1}$ de FDN; $24 \mathrm{~g} \mathrm{~kg}^{-1}$ de $\mathrm{EE} ; 0,5 \mathrm{~g} \mathrm{~kg}^{-1}$ de cálcio; e $2,4 \mathrm{~g} \mathrm{~kg}^{-1}$ de fósforo, segundo valores tabelados contidos no NRC (2001).

O fornecimento apenas de sal branco (e não de mistura mineral completa) para as novilhas do sistema 2 durante 92 dias funcionou como "suplementação testemunha", ou seja, sem os ingredientes proteicos e energéticos (fubá de milho, farelo de soja e ureia), porém também sem outras fontes de nutrientes minerais que pudessem interferir nos resultados de desempenho animal, em função dos tratamentos.

Os consumos médios diários de suplemento proteico-energético e de sal branco foram descritos como médias por novilha em cada sistema de produção. Dessa forma, os consumos foram estimados com precisão de $1 \mathrm{~g}$ (suplemento e sal branco pesados em balança de precisão) e frequência semanal, com base na diferença entre a quantidade fornecida e as sobras nos cochos. Para avaliação do peso corporal médio (PCM) e do ganho de peso médio diário (GMD), as novilhas foram pesadas a cada 21 dias, após jejum completo (líquidos e sólidos) de 12 horas. As pesagens foram ordenadas de 1 a 8 para as respectivas datas: $21 / 06 ; 12 / 07 ; 02 / 08 ; 23 / 08$; 13/09; 04/10; 25/10 e 15/11. Já para GMD, os períodos de avaliação foram de 1 a 7 , respectivamente: 1 : 21/06 a $12 / 07 ; 2: 12 / 07$ a 02/08; 3: $02 / 08$ a 23/08; 4: 23/08 a 13/09; 5: 13/09 a $04 / 10 ; 6: 04 / 10$ a $25 / 10$ e $7: 25 / 10$ a $15 / 11$.

Os dados de PCM e de GMD foram analisados por meio do procedimento MIXED do pacote estatístico do SAS $^{\circledR} \quad$ (Statistical Analysis System), versão 9.2, para Windows. As análises de variância foram feitas com base em sistema de produção e data de avaliação (efeitos fixos) e suas interações (efeitos aleatórios). As médias dos tratamentos foram estimadas pelo LSMEANS e comparadas por PDIFF $(\mathrm{P}<0,05)$.

Com base nos dados de consumo de suplemento, PCM e GMD, foi realizada análise econômica dos sistemas de produção, por meio da metodologia de orçamento parcial comparativo, conforme proposto por Noronha (1981). O sistema 1 foi definido como substituível, uma vez que se configura como estratégia comum fornecer suplemento proteico-energético durante toda a estação seca do ano. Foram realizados levantamentos das receitas obtidas e dos custos 
não realizáveis do sistema 1 , além do balanço da mudança (aumento ou redução do lucro), das receitas obtidas e dos custos adicionais na implantação do sistema 2. Os dados foram tabulados em planilhas eletrônicas do Microsoft Excel®, e os resultados obtidos após a análise dos benefícios e dos custos na comparação de ambos os sistemas de produção.

Para determinação dos indicadores econômicos de rentabilidade VPL e TIR, em ambos os sistemas de produção, foram considerados os custos de produção segundo Reis (2002) e a depreciação conforme Pulici et al. (2016). Na determinação do VPL, foram aplicadas, sob o fluxo de caixa de cada sistema de produção, diferentes taxas de desconto (4, 6, 8 e 10\%) ao ano. Para TIR, o resultado obtido foi comparado à taxa mínima de atratividade de 2,06\%, obtida pela diferença da remuneração da caderneta de poupança $(8,35 \%)$ pelo índice nacional de preços ao consumidor amplo acumulado em 2016 $(6,29 \%)$, segundo o Portal Brasil (Relatório do ano de 2016).

Os fluxos de caixa foram obtidos computando-se as entradas e as saídas observadas durante os cinco meses envolvidos na pesquisa (Ibre/FGV, 2016). Esses valores foram deflacionados pelo índice geral de preços - disponibilidade interna (IGP-DI), publicados pela Fundação Getúlio Vargas (Ibre/FGV, 2016), atualizando-se os preços monetariamente. As saídas foram compostas por: valores imobilizados em terras, animais, instalações e equipamentos; imposto territorial rural; gastos com energia elétrica, fertilizantes, insumos utilizados na suplementação e medicamentos; remuneração fixa do funcionário, do técnico responsável e do proprietário. Neste item, foram consideradas atividades de 60 minutos diários sobre o valor de um salário mínimo para o funcionário, dois salários para o técnico responsável e três para o proprietário, para o ano de 2016, segundo o Portal Brasil (Relatório do ano de 2016). Foram considerados 15 anos de vida útil para curral, balança de pesagem e tronco de contenção; 10 (dez) anos para mourão de eucalipto tratado, arame galvanizado e cochos. As entradas foram representadas pela venda dos animais e da terra ao final do experimento. Foi atribuída valorização da terra em $10 \%$ anuais, segundo revisão de Oliveira e Ferreira (2014).

\section{RESULTADOS E DISCUSSÃO}

O consumo de suplemento proteico-energético, para ambos os sistemas de produção (Tab.1), foi menor que o esperado $\left(375 \mathrm{~g} \mathrm{UA}^{-1} \mathrm{dia}^{-1}\right.$, ou $0,1 \%$ do peso corporal). Isso possivelmente ocorreu devido às proporções de ureia e sal branco (100 e $150 \mathrm{~g} \mathrm{~kg}^{-1}$, respectivamente) no suplemento, uma vez que esses ingredientes são os principais limitantes de consumo na SPE (Malafaia et al., 2003; Gomes et al., 2015). Além disso, foi observada maior eficiência de conversão de suplemento consumido em ganho de peso (Tab.1) para as novilhas do sistema 2, provavelmente, pelo efeito de crescimento compensatório pós-período de restrição nutricional (Barbero et al., 2016).

Tabela 1. Consumo médio de sal branco (SB), suplemento proteico-energético (SPE) e ganho médio diário por quantidade de suplemento consumido (gGMD $\mathrm{gSPE}^{-1}$ ) de novilhas Nelore submetidas a 147 e 55 dias de SPE

\begin{tabular}{lcc}
\hline Variáveis $^{1}$ & $\begin{array}{c}\text { Sistema } \\
1^{2}\end{array}$ & Sistema $2^{3}$ \\
\hline SB $\left(\mathrm{g} \mathrm{UA}^{-1} \mathrm{dia}^{-1}\right)$ & 0 & 42 \\
$\mathrm{SPE}\left(\mathrm{g} \mathrm{UA}^{-1} \mathrm{dia}^{-1}\right)$ & 260 & 181 \\
gGMD gSPE $^{-1}$ & 1,35 & 1,95 \\
\hline${ }^{1}$ Estimativas descritivas, com & resultados \\
representativos da média das novilhas em todo o \\
período de consumo dos respectivos suplementos. \\
${ }^{2} 147$ dias de suplementação proteico-energética. ${ }^{3} 55$ \\
dias de suplementação proteico-energética.
\end{tabular}

Houve interação $(\mathrm{P}<0,0001)$ entre sistema de produção e data de avaliação para peso corporal médio (PCM) e ganho de peso médio diário (GMD) durante o período experimental. Os resultados podem ser observados na Fig. 1 e na Tab. 2, respectivamente.

Os pesos corporais médios (PCM) das novilhas foram semelhantes para ambos os sistemas de produção nas pesagens $1,2,3,4$ e 8 , provavelmente, em razão da similaridade de oferta e qualidade da forragem nesses momentos (Fig. 1). Os PCM aumentaram, em ambos os sistemas, do início para o final do período experimental, possivelmente, em função do maior consumo de PB devido ao fornecimento do suplemento proteico-energético, uma vez que, garantida a adequada oferta de forragem, a PB é o nutriente mais limitante no desempenho produtivo de ruminantes durante o período seco 
do ano (Van Niekerk e Jacobs, 1985). Esses resultados são semelhantes àqueles obtidos por Carvalho et al. (2014), que suplementaram bezerros Nelore com SPE, em pastos de Urochloa brizantha cv. Marandu.

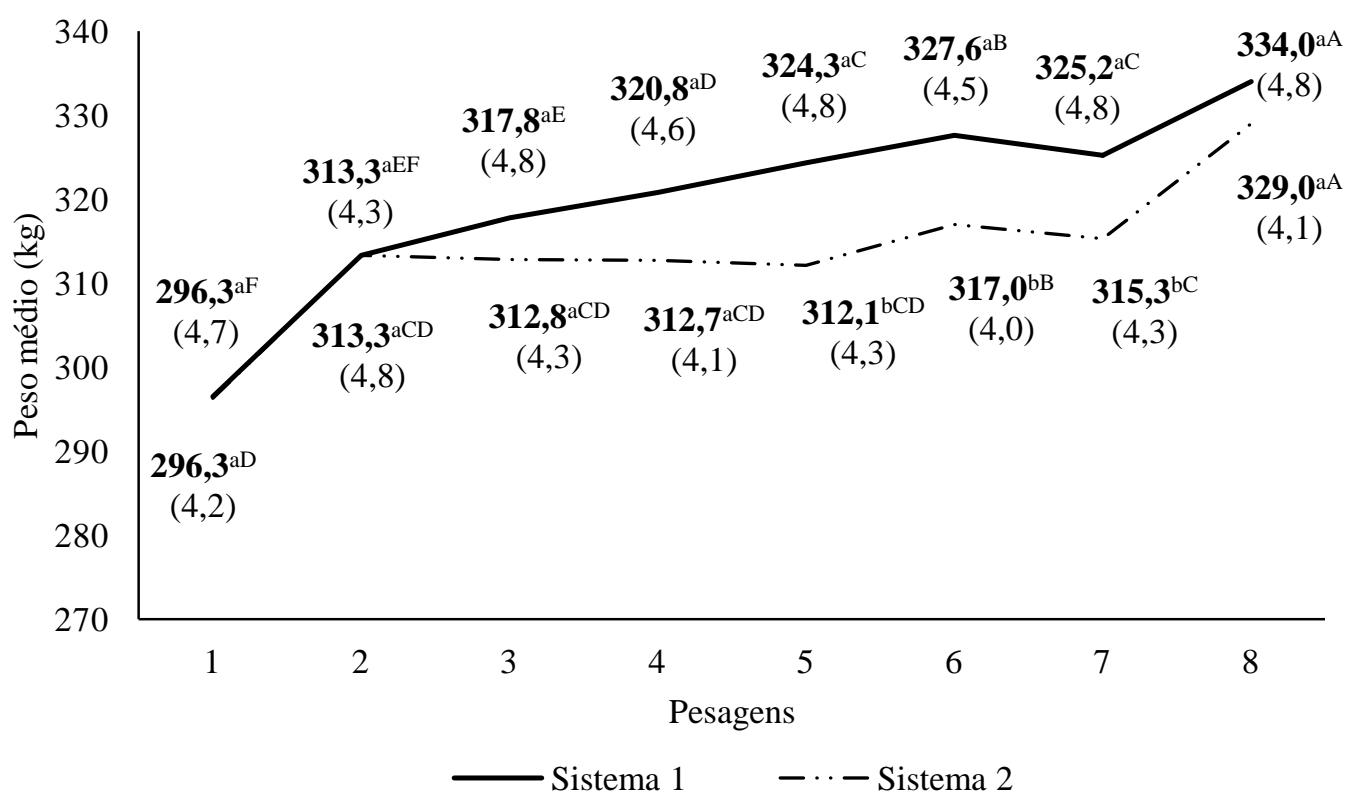

Figura 1. Peso corporal médio das novilhas submetidas a 147 e 55 dias SPE durante o período seco do ano. Médias seguidas por mesma letra, minúscula no eixo vertical e maiúscula no eixo horizontal, não diferem entre si pela PDIFF $(\mathrm{P}<0,05)$. Valores entre parênteses representam o erro-padrão da média. Pesagem 1: 21/06; 2: 12/07; 3: 02/08; 4: 23/08; 5: 13/09; 6: 04/10; 7: 25/10 e 8: 15/11.

Por outro lado, os maiores PCM obtidos para o sistema 1 em comparação ao sistema 2, nas pesagens 5, 6 e 7 (Fig. 1), ocorreram em razão do fornecimento e consumo de suplemento proteicoenergético de 21/06 até 21/09/2016, intervalo de tempo no qual o sistema 2 não recebeu SPE. Tal fato resultou em maiores GMD para o sistema 1 nos períodos 2, 3 e 4 de avaliação (Tab. 2), o que refletiu nos maiores PCM subsequentes. Isso evidenciou o efeito aditivo (sinérgico e positivo) do SPE sobre o consumo de forragem de baixa qualidade no período seco do ano (Reis et al., 2013). Esses resultados são semelhantes àqueles obtidos por Barros et al. (2014), que relataram superioridade de $151 \mathrm{~g}$ novilha ${ }^{-1} \mathrm{dia}^{-1}$ de GMD para novilhas mestiças Nelore consumindo SPE sobre outras consumindo apenas mistura mineral, durante 84 dias do período seco do ano.

O GMD somente foi semelhante entre sistemas de produção no período 1 (21/06 a 12/07), possivelmente devido à similar oferta de forragem inicial (21/06) e à falta de efeito da
SPE sobre o consumo de forragem das novilhas até o final desse período (12/07). Os menores PCM obtidos na pesagem 7 em relação à 6 (Fig. 1) e GMD do período 6 em relação ao 5 (Tab. 2) possivelmente se deveram à "diarreia da primavera", que ocorre quando há mudança repentina na qualidade da forragem, seguida de alteração das cargas iônicas no ambiente ruminal, aumento da taxa de passagem da forragem no trato gastrintestinal, irritação nas mucosas do intestino e consequente perda de peso dos animais (Fernandes, 2014).

Ressalta-se que a falta de fornecimento do suplemento não proporcionou redução dos PCM nas pesagens 2 a 5 (Fig. 1) para o sistema 2, uma vez que bovinos submetidos à restrição nutricional de ordem qualitativa ainda são capazes de manter peso corporal quando a oferta de forragem é adequada (Malafaia et al., 2003). Já na última pesagem (8), os valores de PCM foram semelhantes entre os sistemas de produção, e os GMD foram maiores para o 
sistema 2 nos períodos 5, 6 e 7 (Tab. 2). O efeito observado pode ser atribuído ao "crescimento compensatório" (Barbero et al., 2016), uma vez que, após o período com menor GMD (Tab. 2), foi observado maior ganho de peso para os animais do sistema 2 ao receberem SPE (Fig. 1).

Tabela 2. Ganho de peso médio diário (GMD) de novilhas Nelore submetidas a 147 e 55 dias SPE (sistemas 1 e 2, respectivamente) durante $o$ período seco do ano

\begin{tabular}{ccc}
\hline \multicolumn{3}{c}{ GMD $\left(\mathrm{g} \mathrm{novilha}^{-1} \mathrm{dia}^{-1}\right)$} \\
\hline $\begin{array}{c}\text { Período de } \\
\text { avaliação }\end{array}$ & Sistema 1 & Sistema 2 \\
\hline 1 & $592^{\mathrm{aA}}(10)$ & $598^{\mathrm{aA}}(9)$ \\
2 & $179^{\mathrm{aC}}(7)$ & $-21^{\mathrm{bD}}(6)$ \\
3 & $130^{\mathrm{aD}}(8)$ & $5^{\mathrm{bD}}(9)$ \\
4 & $172^{\mathrm{aC}}(8)$ & $5^{\mathrm{bD}}(9)$ \\
5 & $164^{\mathrm{bC}}(7)$ & $231^{\mathrm{aC}}(7)$ \\
6 & $-227^{\mathrm{bE}}(12)$ & $-189^{\mathrm{aE}}(12)$ \\
7 & $370^{\mathrm{bB}}(8)$ & $480^{\mathrm{aB}}(8)$ \\
\hline
\end{tabular}

${ }^{1}$ Período de avaliação 1: 21/06 a 12/07; 2: 12/07 a 02/08; 3: $02 / 08$ a 23/08; 4: 23/08 a 13/09; 5: $13 / 09$ a 04/10; 6: $04 / 10$ a 25/10 e 7: 25/10 a 15/11. Médias seguidas por mesma letra, minúscula na linha e maiúscula na coluna, não diferem entre si pela PDIFF $(\mathrm{P}<0,05)$. Valores entre parênteses representam o erropadrão da média.

Essas respostas são similares àquelas obtidas por Malafaia et al. (2007), que estudaram novilhos mestiços Holandês-zebu suplementados com SPE durante 59 dias e 125 dias, e observaram pesos médios semelhantes ao final do experimento (398,1 e 401,6kg, respectivamente).

Foram obtidos resultados positivos em ambos os sistemas para o VPL sob a taxa de desconto de $4 \%$ a.a (Tab. 3). Considerando-se a TIR, ambos os sistemas de produção apresentam rentabilidade superior ao rendimento real da caderneta de poupança $(2,06 \%$ a.a. $)$ no mesmo período, rendimento este considerado como a taxa mínima de atratividade. Por resultar em maior TIR, o sistema 2 foi o mais indicado para investimento, pois permitiu ao pecuarista maior remuneração do capital investido.

No estudo de Peripolli et al. (2016), foram obtidos valores de R\$178.855,89 para o VPL e de $12,14 \%$ a.a. para a TIR, em sistema de recria e engorda de bovinos Nelore a pasto, com duração de 24 meses, ganho de peso médio diário (GMD) de $398 \mathrm{~g} \mathrm{UA}^{-1}$ animal $^{-1}$ dia e SPE nos períodos secos do ano. Nesse caso, os autores reportaram que a fase de recria no período seco do ano, mesmo com SPE, foi marcada pela manutenção do peso corporal dos animais. Já os resultados de TIR para os sistemas 1 e 2 foram inferiores àqueles apresentados pelos autores. Contudo, deve-se considerar que estratégias de reduzido nível tecnológico são insustentáveis em curto prazo (Figueiredo et al., 2007), fato que ocorreu no experimento ao se considerar um horizonte de cinco meses, SPE de baixo consumo e desempenho moderado (GMD de $244 \mathrm{~g} \mathrm{UA}^{-1} \mathrm{dia}^{-1}$ ).

Tabela 3. Valor presente líquido (VPL) e taxa interna de retorno (TIR) em comparação à taxa mínima de atratividade (TMA) para os sistemas 1 e 2 .

\begin{tabular}{ccc}
\hline \multicolumn{3}{c}{ VPL } \\
\hline $\begin{array}{c}\text { Taxas de } \\
\text { desconto }(\%)\end{array}$ & Sistema $1^{1}$ & Sistema $2^{2}$ \\
\hline 4 & $\mathrm{R} \$ 65,73$ & $\mathrm{R} \$ 440,67$ \\
6 & $-\mathrm{R} \$ 939,89$ & $-\mathrm{R} \$ 609,53$ \\
8 & $-\mathrm{R} \$ 1.918,95$ & $-\mathrm{R} \$ 1.632,00$ \\
10 & $-\mathrm{R} \$ 2.872,63$ & $-\mathrm{R} \$ 2.627,95$ \\
\hline TIR & 4,13 & 4,83 \\
\hline
\end{tabular}

${ }^{1} 147$ dias de suplementação proteico-energética. ${ }^{2} 55$ dias de suplementação proteico-energética.

Por outro lado, a maior eficiência econômica observada no sistema 2 em relação ao sistema 1 se deve, sobretudo, à relação entre o ganho de peso dos animais e o consumo de suplemento. Isso porque elevados consumos de suplemento aliados à menor conversão alimentar promovem desempenhos econômicos menos satisfatórios (Figueiredo et al., 2007). Nesse sentido, foram observados maiores GMD por quantidade de suplemento consumido (gSPE) para o sistema 2 (Tab. 1), fato que determinou maiores valores de VPL e TIR nesse sistema de produção.

Para o orçamento parcial comparativo, verificouse balanço econômico positivo (aumento do lucro) de R \$ 25,26 por animal para substituição do sistema 1 pelo 2 (Tab. 4), proporcionado pela maior eficiência na conversão do suplemento em ganho de peso médio diário no sistema 2. 
Tabela 4. Orçamento parcial comparativo da substituição do sistema $1^{1}$ pelo sistema $2^{2}$

\begin{tabular}{|c|c|c|c|}
\hline Custos da mudança & $\mathrm{R} \$$ & Benefícios da mudança & $\mathrm{R} \$$ \\
\hline $\begin{array}{l}\text { A - Receitas não realizáveis (sistema } \\
\text { 1) }\end{array}$ & & A - Receitas adicionais (sistema 2) & \\
\hline 1 - venda das novilhas & $24.886,54$ & 1 - venda das novilhas & $30.643,06$ \\
\hline B - Custos adicionais (sistema 2) & & B - Custos não realizáveis (sistema 1) & \\
\hline 2 - ureia & 576,00 & $2-$ ureia & 576,00 \\
\hline 3 - varredura (fertilizante) & 375,00 & 3 - varredura (fertilizante) & 375,00 \\
\hline 4 - farelo de soja & 21,00 & 4 - farelo de soja & 85,77 \\
\hline 5 - fubá de milho & 38,36 & 5 - fubá de milho & 156,61 \\
\hline 6 - ureia $(\mathrm{SPE})$ & 9,14 & 6 - ureia $(\mathrm{SPE})$ & 37,29 \\
\hline 7 - sal branco $(\mathrm{NaCl})$ & 4,87 & 7 - sal branco $(\mathrm{NaCl})$ & 19,89 \\
\hline 8 - ivermectina & 215,00 & 8 - ivermectina & 215,00 \\
\hline 9 - terramicina & 21,90 & $9-$ terramicina & 21,90 \\
\hline 10 - dexametasona & 7,00 & 10 - dexametasona & 7,00 \\
\hline 11 - brinco marcador & 51,44 & 11 - brinco marcador & 51,44 \\
\hline $12-$ trator (serviço) & $1.200,00$ & $12-$ trator $($ serviço) & $1.200,00$ \\
\hline 13 - depreciação (cerca) & 0,53 & 13 - depreciação (cerca) & 0,53 \\
\hline 14 - compra das novilhas & $27.389,40$ & 14 - compra das novilhas & $21.911,89$ \\
\hline Subtotal $(\mathrm{A}+\mathrm{B})$ & $54.796,18$ & Subtotal $(A+B)$ & $55.301,38$ \\
\hline Balanço (+/- lucro) & 505,20 & Balanço (+/- lucro) & - \\
\hline Balanço por animal (+/- lucro) & 25,26 & Balanço por animal (+/- lucro) & - \\
\hline Total & $55.301,38$ & Total & $55.301,38$ \\
\hline
\end{tabular}

${ }^{1} 147$ dias de suplementação proteico-energética. ${ }^{2} 55$ dias de suplementação proteico-energética.

Nesse sentido, Lopes (2016) realizou análise bioeconômica de sistemas de novilhos de corte da raça Britânica (peso médio inicial de $200 \pm 5 \mathrm{~kg}$ ) recriados em pastagens nativas, os quais se diferenciavam pelos períodos de restrição alimentar. Assim, os sistemas de produção eram de zero, 90, 120 e 150 dias de restrição pós-desmama, com fornecimento de suplemento múltiplo (consumo de $0,7 \%$ do peso corporal) após os respectivos períodos de restrição. Foi observado maior lucro por animal para o sistema de 90 dias de restrição alimentar ( $\mathrm{R} \$ 398,90)$, em comparação aos demais ( $\mathrm{R} \$$ 303,64; R\$ 257,58; e R\$219,19 para zero, 120 e 150 dias de restrição, respectivamente), devido ao efeito de crescimento compensatório, também observado no presente estudo. Vale enfatizar que o período de restrição alimentar neste experimento foi de 92 dias para o sistema 2, intervalo de tempo próximo aos 90 dias indicados por Lopes (2016) como financeiramente mais eficiente.

O balanço econômico positivo para o sistema 2 pode ser explicado pelo fato de ter ocorrido menor consumo de suplemento proteicoenergético em comparação ao sistema 1 (Tab. 1), além de os custos adicionais (sistema 2) dos insumos referentes ao SPE (ureia, sal branco, farelo de soja e fubá de milho) terem sido inferiores aos custos não realizáveis (sistema 1), em razão, sobretudo, da maior conversão do suplemento em ganho de peso médio diário para o sistema 2 (Tab. 1).

Portanto, garantida a oferta de forragem, a combinação estratégica de fornecimento de sal branco na fase inicial da estação seca, seguida por uma SPE na fase final desse período, resultou em maior lucro, redução dos custos com suplementação e, ao menos, manutenção das receitas.

\section{CONCLUSÕES}

A suplementação proteico-energética durante 147 ou 55 dias proporciona peso corporal médio semelhante entre novilhas Nelore em pastagem diferida de Urochloa decumbens, ao final da fase de recria. A suplementação proteico-energética durante 55 dias propicia maior retorno financeiro do capital investido e apresenta-se como sistema de recria de novilhas mais atrativo para investimento. 


\section{AGRADECIMENTOS}

O presente trabalho foi realizado com apoio da Coordenação de Aperfeiçoamento de Pessoal de Nível Superior Brasil (CAPES) - Código de Financiamento 001.

\section{REFERÊNCIAS}

ANDRADE, V.J. Efeito de diferentes épocas de início da estação de monta sobre o comportamento reprodutivo de novilhas de corte. Arq. Bras. Med. Vet. Zootec., v.42, p.93-101, 1990.

BARBERO, R.P.; BARBOSA, M.A.A.F.; FORTALEZA, A.P.S. et al. Suplementação com fontes proteicas na terminação de novilhas de corte: estudo bioecônomico. Ciênc. Anim. Bras., v.17, p.54-59, 2016.

BARROS, L.V.; MONTEIRO, A.L.G.; POLI, C.H.E.C. et al. Desempenho produtivo $\mathrm{e}$ nutricional de novilhas de corte em pastejo suplementadas no período da seca e/ou no período de transição seca-águas. Semin. Ciênc. Agrár., v.35, p.2655-2672, 2014.

CARVALHO, D.M.G.; CABRAL, L.S.; ZERVOUDAKIS, J.T. et al. Eficiência bioeconômica da suplementação de novilhos em pastagens de Capim Marandu. Semin. Ciênc. Agrár., v.35, p.2685-2698, 2014.

CONTADOR, F.P. Avaliação social de projetos. 2.ed. São Paulo: Atlas, 1988. 315p.

FERNANDES, R.M. Relação nitrogênio não proteico e proteína verdadeira em suplementos na recria de bezerros Nelore. 2014. 75f. Dissertação (Mestrado em Zootecnia) Universidade Estadual Paulista Júlio de Mesquita, Jaboticabal, SP.

FIGUEIREDO, D.M.; OLIVEIRA, A.S.; SALES, M.F.L. et al. Análise econômica de quatro estratégias de suplementação para recria e engorda de bovinos em sistema pastosuplemento. Rev. Bras. Zootec., v.36, p.14431453, 2007.
GOMES, R.C.; NUÑEZ, A.J.C.; MARINO, C.T.; MEDEIROS, S.R. Estratégias alimentares para gado de corte: suplementação a pasto, semiconfinamento e confinamento. In: MEDEIROS, S.R.; GOMES R.C.; BUNGENSTAB, D.J. Nutrição de bovinos de corte: fundamentos e aplicações. Brasília: Embrapa, 2015. 176p.

LOPES, R.B. Avaliação bioeconômica do crescimento compensatório em sistemas de produção de bovinos de corte. 2016. 77f. Dissertação (Mestrado em Zootecnia) Universidade Federal do Rio Grande do Sul, Porto Alegre, RS.

MALAFAIA, P.; CABRAL, L.S.; VIEIRA, R.A.M. et al. Suplementação proteico-energético para bovinos criados em pastagens: aspectos teóricos e principais resultados publicados no Brasil. Livest. Res. Rural Develop., v.15, p.1-35, 2003.

MALAFAIA, P.; GONÇALVES, J.C.S.; FERREIRA, A.E.; MORENZ, M.J.F. Desempenho de bovinos mestiços leiteiros submetidos à suplementação protéico-energética em diferentes meses da estação da seca. Rev. Bras. Med. Vet., v.29, p.69-72, 2007.

MARINO, C.T.; MEDEIROS, S.R. Minerais e vitaminas na nutrição de bovinos de corte. In: MEDEIROS, S.R.; GOMES, R.C.; BUNGENSTAB, D.J. (Eds.). Nutrição de bovinos de corte: fundamentos e aplicações. Brasília: Embrapa, 2015. 176p.

MEDEIROS, S.R.; ALMEIDA, R.; LANNA, D.P.D. Manejo da recria - eficiência do crescimento da desmama à terminação. In: PIRES, A.V. (Ed.). Bovinocultura de corte. Piracicaba: FEALQ, 2010. v.1, 760p.

MOTA, E.P.; MENDES, F.L.; SHIROTA, R. Viabilidade de implantação de ureias revestidas no cultivo de milho para estado de São Paulo. Rev. iPeceg., v.1, p.22-38, 2015.

MOTA, V.A.C. Efeito de diferentes ofertas de forragem na terminação de bovinos nelore recebendo alta suplementação recriados com diferentes taxas de ganho. 2015. 68f. Dissertação (Mestrado em Zootecnia) - Universidade Estadual Paulista Júlio de Mesquita, Jaboticabal, SP. 
NORONHA, J.F. (Ed.). Projetos agropecuários: administração financeira, orçamentação e avaliação econômica. Piracicaba: FEALQ, 1981. $274 p$.

OLIVEIRA, N.A.P.; FERREIRA, L.R. Determinantes do preço da terra no Brasil. Rev. Política Agríc., v.13, p.58-74, 2014.

PERES, A.A.C.; SANTOS, A.A.; CARVALHO, C.A.B.; BRANDALISE, N. Análise financeira de sistemas de produção para novilhas em pastagem de Brachiaria brizantha 'Xaraés' suplementadas com mistura mineral. Arch. Zootec., v.64, p.123-130, 2015.

PERIPOLI, E.; OLIVEIRA, M.S.L.; BALDI, F. et al. Valores econômicos para sistemas de recria e engorda de bovinos Nelore e cruzado. Arch. Zootec., v.65, p.145-154. 2016.

PULICI, P.H.S.; OLIVEIRA, S.M.; FEITOSA, B.M. et al. Custo de produção na terminação de novilhas em sistema de pastejo rotacionado e suplementação, Estado de São Paulo, Brasil. Rev. Espacios, v.37, p.1-14, 2016.

REIS, R.A.; RUGGIERI, A.C.; OLIVEIRA, A.A. et al. (Eds.). Forragicultura: ciência, tecnologia e gestão dos recursos forrageiros. Jaboticabal: Maria de Lourdes Brandel - ME, 2013. 714p.
REIS, R.P. (Ed.). Fundamentos de economia aplicada. Rev. ampl. Lavras: FAEPE, 2002. 95p.

RELATÓRIO do ano de 2016. Portal Brasil. Caderneta de poupança. Índices mensais. Disponível em: <http://www.portalbrasil.net/poupanca_mensal.h tml >. Acesso em: 16 jan. 2017.

SAINZ R.D. Why does feed restriction improve efficiency? In: Symposium: Feed intake by feedlot cattle, 1995, Stillwater. Anais... Oklahoma: [s.n], 1995. p.175-184.

SILVA, F.F. SÁ, J.F.; SCHIO, A.R. et al. Suplementação a pasto: disponibilidade e qualidade $\mathrm{x}$ níveis de suplementação $\mathrm{x}$ desempenho. Rev. Bras. Zootec., v.38, p.371389, 2009.

VAN NIEKERK, B.D.H.; JACOBS, G.A Protein, energy and phosphorus supplementation of cattle fed low-quality forage. S. Afr. J. Anim. Sci., v.15, p.133-136, 1985.

ZERVOUDAKIS, J.T.; PAULINO, M.F.; CABRAL, L.S. et al. Parâmetros nutricionais de novilhos sob suplementação em sistema de autocontrole de consumo no período de transição águas-seca. Rev. Bras. Zootec., v.39, p.2753$2762,2010$. 